importance of cultural stigma, personal visibility, community networks, and positive identity. Journal of Personality, 65, 599-624.

Huijts, T. \& Kraaykamp, G. (2012) Formal and informal social capital and self-rated health in Europe: a new test of accumulation and compensation mechanisms using a multi-level perspective. Acta Sociologica, 55, 143-158.

Meyer, I. H. (2003) Prejudice, social stress, and mental health in lesbian, gay, and bisexual populations: conceptual issues and research evidence. Psychological Bulletin, 129, 674-697.

Parker, R. (2001) Sexuality, culture, and power in HIV/AIDS research. Annual Review of Anthropology, 30, 163-179.
Remafedi, G. (1990) Fundamental issues in the case of homosexual youth. Medical Clinics of North America, 74, 1169-1179.

Sandfort, T. G. M., de Graaf, R., Bijl, R. V., et al (2001) Same-sex sexual behaviour and psychiatric disorders. Findings from the Netherlands mental health survey and incidence study (NEMESIS). Archives of General Psychiatry, 58, 85-91.

van den Akker, H., van der Ploeg, R. \& Scheepers, P. (2013) Disapproval of homosexuality: comparative research on individual and national determinants of disapproval of homosexuality in 20 European countries. International Journal of Public Opinion Research, 25, 64-86.

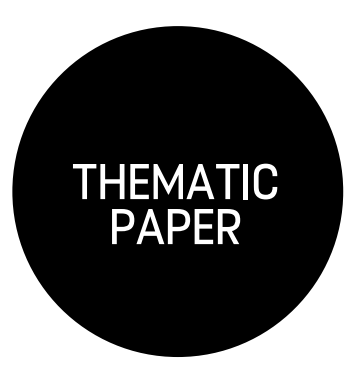

HEALTH AND HOMOSEXUALITY

\title{
Attitudes towards sexual minorities among Chinese people: implications for mental health
}

\author{
Joseph Wu $\mathrm{W}^{1}$ and Diana K. Kwok ${ }^{2}$
}

'Assistant Professor, Department of Applied Social Studies,

City University of Hong Kong.

Kowloon, Hong Konc

email joseph.wu@cityu.edu.hk

${ }^{2}$ Assistant Professor, Department

of Applied Social Studies, City

University of Hong Kong
Heterosexuality continues to be regarded and adopted as a norm in the majority of Asian societies. In Hong Kong, lesbians and gay men are still encountering unfavourable attitudes from the general public (such as stereotyping and discrimination). This paper briefly reviews the legal and cultural context and notes in particular the situation in schools.

Despite the fact that homosexuality has been removed from the Diagnostic and Statistical Manual of Mental Disorders as a kind of mental illness since 1973 by the American Psychiatric Association, heterosexuality continues to be regarded (and adopted) as the norm in the cultures of a majority of Asian societies (Lim \& Johnson, 2001). For instance, in Hong Kong, lesbians and gay men are still encountering unfavourable attitudes from the general public (such as stereotyping and discrimination) (Hong Kong Christian Institute, 2006; see also Human Rights Watch, 2001).

\section{Attitudes towards sexual minorities}

In Hong Kong, homosexuality has been decriminalised since 1991 and has been removed from the Chinese Diagnostic Manual of Mental Disorders since 2001 (Chan, 2008). Nonetheless, some Hong Kong medical professionals are still of the view that homosexuality is pathological. That is, gay and lesbian individuals have been perceived to be suffering from a pathological problem for no reason other than their sexual orientation. In a 2009 survey of 425 medical students from the University of Hong Kong, most respondents had fairly negative attitudes towards gay men and lesbians (Kan et al, 2009). Similarly, a survey was conducted among a sample of 462 Chinese social work students from three Hong Kong government-funded universities accredited by the Hong Kong Social Workers Registration Board for institutional training of practitioners in Hong Kong. Again, unfavourable attitudes towards lesbians and gay men were reported (Kwok et al, 2013). Among the five personal variables included in that study (sex, year of study at the university, religious affiliation, experience of volunteering services, and attendance on a course relating to sexual diversity), religious affiliation contributed the most in predicting differences in attitudes towards lesbians and gay men. Specifically, those in the study with Christian beliefs reported more negative attitudes towards lesbians and gay men than those without any religious affiliation. Other variables such as sex and extent of contact with homosexuals were also shown to have an impact on these unfavourable attitudes towards homosexuals. Those who were male (compared with their female counterparts) and who had no contact with sexual minorities (compared with those who had this kind of experience) reported more unfavourable attitudes towards sexual minorities.

In a comparative study in which 231 lesbians from Hong Kong and 199 lesbians from mainland China were interviewed, Chow \& Cheng (2010) reported that lesbians were far more likely to be open about their sexual orientation with their friends than with their families. Although $95 \%$ of interviewees had told their friends of their sexual orientation, only $60 \%$ felt able to disclose this information to their families. A major reason was that the interviewees would expect severe damage to (or even a permanent loss of) some pivotal 
interpersonal relationships if they did so (such as being completely rejected by their parents).

\section{Legislative context}

In 2009, the government of Hong Kong initiated a public consultation about a proposal to include lesbian and gay couples within the ambit of the Amended Domestic Violence Ordinance. After a number of hot debates among stakeholders, this Ordinance was eventually amended as the Domestic and Cohabitation Relationships Violence Ordinance (chapter 189) in 2010.

Despite these changes, which signified a more accepting attitude towards sexual minorities, to date there is still a lack of formal legislation on the protection of this group. Without institutional protection against discrimination for lesbians and gay men, negative labelling will persist. For at least some years to come, lesbians and gay men in Hong Kong are likely to remain subject to discrimination and social exclusion; civil rights relating to marriage, adoption and public services are unlikely to be granted. Nowadays, enactment of the AntiDiscrimination Ordinance on sexual orientation is still receiving considerable opposition from a number of Christian groups, with an argument that homosexuality is sinful. Due to the political power of these religious groups, the full inclusion of gay men and lesbians into Hong Kong society continues to be a difficult task.

\section{Sexual minorities at Hong Kong schools}

The negative attitudes towards lesbians and gay men are referred to as 'homophobia' and 'heterosexism'. The former term has been used widely to describe anti-homosexual responses through attitude, prejudice, fear as well as intolerance. Heterosexism is the ideological system that denies, denigrates and stigmatises any non-heterosexual form of behaviour, identity, relationship or community. In a study by Kwok et al (2012), young lesbian and gay students at school reported that their mental health had suffered (for example through depression and isolation) due to internalised homophobia and school heterosexism. The authors were of the opinion that the social exclusion of lesbian and gay students from their mainstream peers was likely due to school counsellors' heterosexual orientation and lack of training; this was compounded by the lack of school anti-bullying policies and a heterosexist school curriculum. The authors recommended that mental health practitioners, such as counsellors, review their code of practice. Ethical principles addressing the potential damage caused to lesbian and gay service users incurred by 'homophobic' thought within the schools counselling services should be stipulated clearly and explicitly in a handbook guiding professional practice. Moreover, the authors also asked for training and supervision for school counsellors in issues of sexual diversity, to increase their awareness of possible prejudicial attitudes towards lesbian and gay clients. As such, counsellors would be in a better position to overcome prejudice in the provision of quality services to sexual minority clients.

\section{Concluding remarks}

As lesbians and gay men are recipients of prejudice from the public, they are burdened with stress, a poor quality of life and diminished self-identity. Stereotyping and discrimination are core obstacles for them to achieve important life goals (such as obtaining competitive employment, and living independently in a safe and comfortable home). As lesbians and gay men are living in heterosexual societies, 'coming out' (admitting that they are homosexuals) is pivotal for their personal growth and development (as it signifies self-recognition and self-assurance) (Corrigan et al, 2009). Unfortunately, in a fairly conservative society like Hong Kong, it needs a lot of courage to make such a decision. In the past few years, several Hong Kong artists and politicians have publicly stated that they are in an intimate relationship with a same-sex partner. An intention behind the action was to fight for fairer treatment from society regarding their sexual orientation. However, to our knowledge, there is still no concrete plan (and certainly no time line) from the government of Hong Kong on legislation against discrimination relating to issues of sexual diversity. Perhaps, in Hong Kong society, to promote equal opportunities among people with diverse sexual orientation, education and publicity could be two useful channels for nurturing greater acceptance and mutual respect.

\section{References}

Chan, P. C. W. (2008) Stonewalling through schizophrenia: an antigay rights culture in Hong Kong? Sexuality and Culture, 12, 71-87.

Chow, P. K. \& Cheng, S. (2010) Shame, internalized heterosexism, lesbian identity, and coming out to others: a comparative study of lesbians in mainland China and Hong Kong. Journal of Counseling Psychology, 57, 92-104.

Corrigan, P. W., Larson, J. E., Hautamaki, J., et al (2009) What lessons do coming out as gay men or lesbians have for people stigmatized by mental illness? Community Mental Health Journal, 45, 366-374.

Hong Kong Christian Institute (2006) A Report on Discriminative Cases on Sexual Minority Groups. Hong Kong Christian Institute.

Human Rights Watch (2001) Hatred in the Hallways: Violence and Discrimination Against Lesbian, Gay, Bisexual, and Transgender Students in U.S. Schools. Human Rights Watch.

Kan, R. W. M., Au, K. P., Chan, W. K., et al (2009) Homophobia in medical students of the University of Hong Kong. Sex Education, 9 , $65-80$

Kwok, D. K., Winter, S. \& Yuen, M. T. (2012) Heterosexism in school: the counseling experience of Chinese tongzhi students in Hong Kong. British Journal of Guidance and Counseling, 40, 561.

Kwok, D. K., Wu, J. \& Shardlow, S. M. (2013) Attitudes towards lesbians and gay men among Hong Kong Chinese social work students. Journal of Social Work Education, 49, 337-352.

Lim, H. \& Johnson, M. M. (2001) Korean social work students attitudes toward homosexuals. Journal of Social Work Education, $37,545-554$. 